\title{
POLÍTICAS PÚBLICAS E O SISTEMA ÚNICO DE ASSISTÊNCIA SOCIAL
}

\section{PUBLIC POLICIES AND THE UNIFIELD SOCIAL ASSISTENCE SYSTEM}

Bruna Carina da Silva Salgado ${ }^{1}$

UFRPE: https://orcid.org/0000-0002-2383-0782

José de Lima Albuquerque ${ }^{2}$

UFRPE: https://orcid.org/0000-0003-0625-5656

Rafaela Rodrigues Lins ${ }^{3}$

UFRPE: https://orcid.org/0000-0003-4319-5402

Eliabe Roberto de Souza ${ }^{4}$

UFRPE: https://orcid.org/0000-0001-6095-3151

Jorge da Silva Correia Neto ${ }^{5}$

UFRPE: https://orcid.org/0000-0001-9977-1267

DOI: 10.21680/1982-1662.2021v4n31ID26447

\section{Resumo}

A relação entre os homens pode ser definida pelo modo capitalista em que estão inseridos, a partir do momento em que a posse privada de meios de produção e a concentração das riquezas nas mãos da minoria da sociedade, acarretam a exploração

\footnotetext{
${ }^{1}$ E-mail: brunacarina28@gmail.com

2 E-mail: Jose.limaa@ufrpe.br

${ }^{3}$ E-mail: rafaela.lins@ufrpe.br

${ }^{4}$ E-mail: elroso2009@gmail.com

${ }^{5}$ E-mail: jorgecorreianeto@gmail.com
} 
e alienação da maioria da sociedade, que não possui meios de produção, gerando uma nova estrutura social. Neste contexto socioeconômico buscou-se investigar como a implementação do Sistema Único de Assistência Social (SUAS) pode contribuir para que a Política de Assistência Social possa ser consolidada como uma efetiva política de proteção social no Brasil. A presente pesquisa apresenta abordagem qualitativa e, quanto aos objetivos é descritiva. No tocante aos procedimentos técnicos de investigação, utilizaram-se as pesquisas bibliográficas e a bibliométrica, por meio da consulta a livros, artigos científicos, sites e artigos publicados no Portal de Periódicos do CAPES no período de 2014 a 2019. A partir da análise dos artigos pesquisados e da revisão de literatura foi possível observar que a criação do SUAS constituiu um importante avanço para consolidação da assistência social como política de inclusão social, visto que vem reforçar as ações que já vinham sendo implementadas por outros dispositivos legais. Conclui-se que o principal foco analítico da política pública está na identificação de que, por meio da implementação do SUAS, a Assistência Social chegará a ser consolidada como uma efetiva política de proteção social.

Palavras-chave: Políticas Públicas. Sistema Único de Assistência Social. Assistência Social.

\begin{abstract}
:
The relationship among men can be defined by the capitalist mode in which they are inserted, from the moment when the private possession of the means of production and the concentration of wealth in the hands of the minority of society, lead to the exploitation and alienation of most of the society, which has no means of production, generating a new social structure. In this context, we sought to investigate how the implementation of the Unified Social Assistance System (SUAS) can contribute so that the Social Assistance Policy can be consolidated as an effective social protection policy in Brazil. This article presents a qualitative approach, and regarding its objectives, it is descriptive. Regarding the technical investigation procedures, bibliographic and bibliometric researches were used, through books, scientific articles, websites, and articles published in the CAPES Journal Portal from 2014 to 2019. From the analysis of the researched articles and from the literature review it
\end{abstract}


was possible to observe, that the creation of the SUAS constituted an advance towards the consolidation of social assistance as a social inclusion policy, since comes to reinforce the actions that were already being implemented by other legal provisions. It is concluded that the main analytical focus of public policy is to identify that through the implementation of SUAS, Social Assistance will come to be consolidated as an effective social protection policy.

Keywords: Public Policy. Single Social Assistance System. Social Assistance.

\section{Introdução}

A relação entre os homens pode ser definida pelo modo capitalista em que estão inseridos, a partir do momento em que a posse privada de meios de produção e a concentração das riquezas nas mãos da minoria da sociedade, acarretam a exploração e alienação da maioria da sociedade, que não possui meios de produção. No contexto brasileiro, como apontam lamamoto (1982) e Carvalho (2006), pode-se dizer que a prática assistencialista desenvolvida historicamente foi, em verdade, uma forma de manutenção do poder pautada na base do favor e com ações pouco efetivas.

Com a promulgação da Constituição da República Federativa do Brasil de 1988 (CF/88), a Assistência Social passa a ser vista como política pública, passando a ser um direito fundamental e social. A partir de então, pode-se observar uma crescente valorização do campo de conhecimento relacionado às políticas públicas, e ainda das instituições, regras e modelos que fomentam a construção e implementação dessas políticas públicas. Alguns determinantes podem ser explicitados para justificar a maior visibilidade da área, dentre os quais merece destaque a adoção das políticas restritivas de gastos, já que essas são predominantes na maioria dos países, com destaque para aqueles considerados em desenvolvimento (LIMA, 2012).

Considerando ainda outro fator, este mais diretamente relacionado aos países em desenvolvimento e de democracia recente, é que, na maioria desses países, em especial os da América Latina, ainda não se conseguiu formar coalizões políticas que tenham tido eficácia mínima no equacionamento do desenho das políticas públicas, que sejam capazes de propiciar o desenvolvimento econômico e concomitantemente promover a inclusão social de grande parte de sua população, principalmente daquelas 
parcelas em situação de vulnerabilidade social (PAULO NETTO, 2005). E as respostas para esse desafio não são fáceis nem claras e muito menos são consensuais.

No Brasil, só a partir da CF/88 a Assistência Social passou a compor o rol das políticas de seguridade social, devidas pelo Estado brasileiro como direito do cidadão que dela necessitar, como forma de proteção às adversidades de insuficiência ou ausência de renda, decorrentes da sociabilidade capitalista em seu atual estágio de desenvolvimento, bem como de inaptidão ao trabalho por situações intergeracionais ou de insuficiência.

O lento processo de institucionalização da Assistência Social pode ser percebido pelas dificuldades de incorporação do Sistema Único de Assistência Social (SUAS), pelas três esferas de governo, a partir de 2005. Essas dificuldades se ampliam no atual cenário de contrarreformas conservadoras levadas a efeito inicialmente no governo Temer. Este artigo trata dessa questão, apresentando como problema de pesquisa compreender como a Política Pública de Assistência Social implantada no Brasil, considerando-se mais especificamente o SUAS, consegue alcançar a efetividade de uma política pública de proteção social.

Como política de proteção social, a Assistência Social deve atuar junto à população em situação de vulnerabilidade em decorrência do processo de produção da pobreza e, portanto, junto aos cidadãos e grupos que estão fora dos mecanismos e sistemas de segurança social obtido pela via do trabalho, do usufruto das políticas públicas (saúde, educação, cultura, habitação e saneamento, entre outras) e da inserção em sociabilidades sociofamiliares (CARVALHO, 2006). A política pública de Assistência Social é vista como um direito do cidadão, e dever do Estado, considerada como uma política não contributiva. Tal política tem como marco a CF/88, por meio dos artigos 203 e 204.

A partir da CF/88 ocorreram outras regulamentações, como a Lei Orgânica da Assistência Social (LOAS), que tem como princípios e diretrizes a Assistência Social organizada num sistema descentralizado e participativo; e o Estatuto da Criança e do Adolescente (ECA). Mais recentemente, a aprovação do Sistema Único da Assistência Social (SUAS) e da Norma Operacional Básica da Assistência Social (NOB) conferem um novo status e um desafio maior à política pública de assistência social.

A implementação do SUAS representou um novo sentido no que diz respeito ao avanço da política pública da Assistência Social, fortalecendo assim, os instrumentos 
de gestão, definindo os critérios para a partilha de serviços, programas e projetos. Sendo assim, poderíamos considerar que o SUAS representa a possibilidade da Assistência Social se consolidar verdadeiramente como uma política pública de proteção social?

A presente pesquisa procura discutir as políticas públicas relacionadas ao Sistema Único de Assistência Social (SUAS), a partir das ações realizadas na Assistência Social, bem como os desafios políticos relacionados à cultura assistencialista enraizada na história da sociedade brasileira. Dessa forma, pretende-se esclarecer a relação do SUAS com a Assistência Social como elemento fundamental para a consolidação da mesma como política de proteção social.

Em consonância ao objetivo geral procurar-se-á analisar a trajetória histórica da Assistência Social no Brasil; identificar as bases normativas da Assistência Social como política pública; relatar o processo de implantação e implementação do SUAS. A presente pesquisa tem uma abordagem qualitativa e quanto aos objetivos é descritiva. No tocante aos procedimentos técnicos foram empregadas as pesquisas bibliográficas e bibliométrica, por meio da consulta de livros e documentos, referentes à trajetória histórica da Assistência Social brasileira, artigos em repositórios científicos, a saber, o Portal de Periódicos da CAPES no período de 2014 a 2019. Empregou-se também a pesquisa documental, por meio da análise dos seguintes documentos legais: $C F / 88$, LOAS, Política Nacional de Assistência Social (PNAS), a Norma Operacional Básica do SUAS (NOBSUAS). Esta pesquisa inicia-se pela contextualização do estudo da importância da implementação do SUAS como medida fundamental para a consolidação da política de assistência social, como política de inclusão social. A partir dessa discussão inicial, procurou-se discutir os conceitos, o ciclo e a importância social das políticas públicas como medidas de proteção social das populações, sobretudo das mais vulneráveis.

O artigo está estruturado em quatro seções, iniciando-se com esta de Introdução, onde também são apresentados os procedimentos metodológicos. Em seguida é apresentada a seção de discussão teórica sobre políticas públicas. Seguem se as seções que apresentam os resultados e as considerações finais relacionadas aos objetivos estabelecidos. 


\section{Políticas Públicas: Conceitos, Ciclo e Importância Social}

Compreender a origem de determinada área do conhecimento é salutar para melhor entender seus desdobramentos e sua trajetória. Quando se trata da política pública, "enquanto área de conhecimento e também como disciplina acadêmica", aponta-se o seu surgimento nos Estados Unidos da América (EUA), o que vem a romper com a tradição da escola europeia de estudos e pesquisas nessa área. Esta tinha enfoque muito maior na análise sobre o Estado e suas instituições do que no que os governos produziam. Deste modo, “na Europa, a área de política pública surgiu muito mais como uma ampliação dos trabalhos que eram realizados sobre o papel do Estado, do Governo produtor de políticas públicas" (GIANEZINI et al., 2016, p.27). Diferentemente ocorreu nos EUA, onde os estudos sobre políticas públicas aconteceram no mundo acadêmico, sem estabelecer relações com as bases teóricas sobre o papel do Estado, estabelecendo uma ligação direta em estudar a ação dos governos.

A área de políticas públicas contou com quatro grandes fundadores; cronologicamente são eles: H. Laswell, H. Simon, C. Lindblom e D. Easton. Entre as contribuições, com Simon foi introduzido o conceito de racionalidade limitada dos decisores públicos. Já Lindblom chega para questionar a ênfase do racionalismo de Laswell e Simon, e propõe a incorporação de outras variáveis à formulação e à análise de políticas públicas, como as relações de poder e a integração entre as diferentes fases do processo decisório. E, por fim, Easton traz como sua contribuição a definição de política pública como um sistema, onde este autor apresenta a política pública quanto ao tipo como sistêmica, quanto ao estágio da política, formulação e implementação e quanto ao foco, interações complexas (RAEDER, 2014).

E, afinal o que são políticas públicas? Para Peters (2016), a política pública é a soma das atividades dos governos, que agem diretamente ou através de delegação, e que influenciam a vida dos cidadãos. O conceito mais utilizado é o de Laswell, ou seja, “decisões e análises sobre política pública implicam responder às seguintes questões: quem ganha o quê, por quê e que diferença faz" (RAEDER, 2014, p. 8).

Mesmo adotando diferentes perspectivas as definições de políticas públicas assumem, em geral, uma visão holística do tema, na perspectiva de que o todo é mais importante do que a soma das partes, e que indivíduos, instituições e interesses contam, mesmo que ocorram diferenças sobre a importância relativa destes fatores. 
No que tange ao ciclo da política pública, é preciso entender que esta é compreendida como um ciclo deliberativo, sendo este formado por vários estágios, que se constituem num processo dinâmico e de aprendizado (RAEDER, 2014). Segundo o citado autor, o ciclo da política pública é constituído dos seguintes estágios: definição de agenda, identificação de alternativas, avaliação e seleção das opções, e, por fim, implementação e avaliação. Ao se analisar as principais vertentes que tratam sobre o ciclo da política pública percebe-se que umas focalizam mais os participantes do processo decisório, e outras, o processo de formulação da política pública. Cada participante e cada processo podem atuar como um incentivo ou como um ponto de veto.

Ao se reportar à importância social das políticas públicas, Lima (2017, p.37), assevera que,

[...] mesmo diante da crise política que assola o país, essas práticas são essenciais para assegurar as transformações sociais e diminuir as desigualdades. É fundamental para se entender os benefícios trazidos para a sociedade e as responsabilidades do Estado, que se compreenda e analise as políticas públicas do país. Estas são por muitas vezes mesmo ignoradas, no entanto, elas são essenciais para o desenvolvimento humano, formação da cidadania e promoção de igualdades.

Ainda conforme Lima (2017), de forma generalista as políticas públicas podem ser definidas como sendo criações de projetos sociais e/ou ações promovidas pelo Estado em parceria com a sociedade, que buscam trazer melhorias e qualidade de vida para as pessoas, gerando uma transformação social. Essas políticas prezam a coletividade, o interesse de todos os públicos, e ocorrem nas mais diferentes áreas, como saúde, educação, lazer, cultura, moradia, transporte, segurança, assistência social dentre outras. Sem políticas públicas que estabeleçam um caminho para as ações públicas, com objetivos e propósitos discutidos e encadeados que prevejam resultados, a ação pública pode ser ineficiente, não gerar resultados, configurando-se como atividades dispersas e voluntariosas e trazendo muito desperdício de dinheiro público.

Nesse contexto, destaca-se a política pública de assistência social, que visa à proteção social da população, já que atua diretamente na garantia de projetos que 
buscam atender às demandas sociais, independente de gênero, raça, escolaridade e renda.

A política de assistência social foi concebida recentemente, mais especificamente na década de 1980, pelo Estado e sociedade brasileira, para a garantia da proteção social para quem dela necessitar. Pressupõe-se que sua construção seja realizada por programas, projetos, serviços e equipamentos para atuar com a população em situação de vulnerabilidade ou risco social. A Lei n.8.742/1993, que trata da Assistência Social, propõe a participação do governo, dos trabalhadores, dos serviços e da população usuária.

No tocante aos achados da pesquisa bibliográfica e bibliométrica, a seção seguinte sintetiza o que os pesquisadores pensam sobre o tema.

\section{Síntese da pesquisa bibliométrica}

Foram consultados os periódicos disponíveis no site Periódicos CAPES, buscando artigos no período de 2014 a 2019. Para realização das buscas foram utilizados os seguintes descritores: Políticas públicas, assistência social, proteção social.

O quadro 1 apresenta o Título dos artigos do corpus final considerado no estudo bibliométrico.

Quadro 1- Título dos artigos do corpus final considerados no estudo bibliométrico

\begin{tabular}{|c|c|}
\hline Artigo & Título \\
\hline 1 & $\begin{array}{l}\text { Formulação da lei do sistema único de assistência social e a legitimação da política } \\
\text { de assistência social }\end{array}$ \\
\hline 2 & $\begin{array}{l}\text { Contrarreforma da seguridade social: rebatimentos sobre a consolidação da } \\
\text { Assistência Social como política pública }\end{array}$ \\
\hline 3 & A Assistência Social como Política Pública \\
\hline 4 & $\begin{array}{l}\text { Pobreza, Desigualdade Social e Território: ambiência de atuação da Política Pública } \\
\text { de AssistênciaSocial }\end{array}$ \\
\hline 5 & O Sistema Único de Assistência Social: desafios à sua implementação \\
\hline 6 & $\begin{array}{l}\text { O Sistema Único de Assistência Social no Brasil: apresentando a pesquisa, } \\
\text { problematizando a política social }\end{array}$ \\
\hline 7 & Políticas de assistência social: entre a produção/governo da vida \\
\hline
\end{tabular}

Fonte: Elaborado pelos autores (2020). 
O quadro 2 apresenta o Objetivo dos artigos do corpus final considerados no estudo bibliométrico. A partir desses objetivos fica claro que a pesquisa brasileira buscava compreender quais fatores e condicionantes poderiam ser desenvolvidos no sentido de potencializar o SUAS como política de proteção social, a partir da contextualização histórica da assistência social brasileira.

\section{Quadro 2 - Objetivos dos artigos do corpus final considerados no estudo bibliométrico}

\begin{tabular}{c|l|}
\hline Artigo & \multicolumn{1}{|c|}{ Objetivo } \\
1 & $\begin{array}{l}\text { Analisar a necessidade de criação de uma Lei específica que contivesse uma } \\
\text { configuração necessária para legitimar uma nova assistência social frente a gestores } \\
\text { das diferentes esferas de governo, agentes públicos, opinião pública e órgãos de } \\
\text { controle, facilitando as mudanças necessárias à sua implementação no âmbito da ad- } \\
\text { ministração pública. }\end{array}$ \\
\hline $\mathbf{2}$ & $\begin{array}{l}\text { Debater sobre se as contrarreformas conservadoras, em curso, poderão descontinuar } \\
\text { o processo de consolidação do SUAS e conduzir a assistência social ao risco de } \\
\text { regressão conservadora às bases que a originaram, como caridade e ajuda. }\end{array}$ \\
\hline $\mathbf{3}$ & $\begin{array}{l}\text { Investigar os motivos que dificultam apesar do grande avanço no tocante ao } \\
\text { reconhecimento da Assistência Social como política pública, a efetivação na prática } \\
\text { desta politica no âmbito do direito social. }\end{array}$ \\
\hline $\mathbf{4}$ & $\begin{array}{l}\text { Analisara proposta do Sistema Único de Assistência Social (SUAS), como nova forma } \\
\text { de efetivação desta política, cujas possibilidades e limites devem ser considerados } \\
\text { tendo em vista o contexto histórico da assistência social brasileira. }\end{array}$ \\
\hline $\mathbf{6}$ & $\begin{array}{l}\text { Refletir sobre os desafios atuais do processo de implementação do SUAS: } \\
\text { descentralização; cofinanciamento; trabalho e capacitação permanente e continuada } \\
\text { dos trabalhadores. }\end{array}$ \\
\hline $\mathbf{7}$ & $\begin{array}{l}\text { Debater sobre as tendências da proteção social em tempos de nova crise capitalista. } \\
\text { Compreender o social, na lógica das políticas de assistência no Brasil, através de um } \\
\text { determinado discurso no tecido social, produzindo realidades por meio de } \\
\text { determinados saberes e práticas. }\end{array}$
\end{tabular}

Fonte: Elaborado pelos autores (2020).

Para traçar um quadro mais geral sobre as pesquisas sobre políticas públicas e o SUAS foi montado o Quadro 3, apresentando o ano e a revista onde os artigos foram publicados, os descritores apontados, seus autores e instituições às quais os mesmos estão ligados. Percebe-se que apenas na Universidade Federal do Maranhão existe um trabalho mais consistente de pesquisa nessa área, já que foram publicados 3 artigos. 
Quadro 3 - Informações dos artigos mais relevantes para este estudo bibliométrico

\begin{tabular}{|c|c|c|c|c|c|c|}
\hline $\begin{array}{l}\text { Arti } \\
\text { go }\end{array}$ & Ano & Publicado em & Descritores & Autores & Instituição & Região \\
\hline 1 & 2017 & $\begin{array}{c}\text { Ciência \& } \\
\text { Saúde Coletiva }\end{array}$ & $\begin{array}{l}\text { Assistência } \\
\text { Social; } \\
\text { SUAS }\end{array}$ & $\begin{array}{c}\text { Ariane Rego de } \\
\text { Paiva; Lenaura de } \\
\text { Vasconcelos Costa } \\
\text { Lobato }\end{array}$ & $\begin{array}{l}\text { Universidad } \\
\text { e Católica } \\
\text { do Rio de } \\
\text { Janeiro; } \\
\text { Escola de } \\
\text { Serviço } \\
\text { Social, } \\
\text { Universidad } \\
\text { e Federal } \\
\text { Fluminense }\end{array}$ & Sudeste \\
\hline 2 & 2018 & $\begin{array}{l}\text { Revista de } \\
\text { Políticas } \\
\text { Públicas }\end{array}$ & $\begin{array}{l}\text { Conservadorism } \\
\text { o, seguridade } \\
\text { social, } \\
\text { assistência } \\
\text { social. }\end{array}$ & $\begin{array}{c}\text { Lília Penha Viana } \\
\text { Silva }\end{array}$ & UFMA & $\begin{array}{c}\text { Nordest } \\
\mathrm{e}\end{array}$ \\
\hline 3 & 2018 & $\begin{array}{c}\text { Revista } \\
\text { Latinoamerican } \\
\text { a de } \\
\text { Estudiosen } \\
\text { Cultura y } \\
\text { Sociedad }\end{array}$ & $\begin{array}{c}\text { Políticas } \\
\text { Públicas. } \\
\text { Assistência } \\
\text { Social. } \\
\text { Assistencialismo } \\
\text {. Estado. }\end{array}$ & $\begin{array}{l}\text { Daniele Bonapace } \\
\text { dos Santos Lencina }\end{array}$ & $\begin{array}{l}\text { Faculdade } \\
\text { São Braz }\end{array}$ & Sul \\
\hline 4 & 2019 & $\begin{array}{l}\text { Revistas 2- } \\
\text { UEPG }\end{array}$ & $\begin{array}{l}\text { Pobreza. } \\
\text { Desigualdade } \\
\text { Social. } \\
\text { Território }\end{array}$ & $\begin{array}{l}\text { Maria Isabele } \\
\text { Duarte de Souza; } \\
\text { Maria do Rosário } \\
\text { de Fátima e Silva }\end{array}$ & UEPG & Sudeste \\
\hline 5 & 2014 & $\begin{array}{l}\text { Revista de } \\
\text { Políticas } \\
\text { Públicas }\end{array}$ & $\begin{array}{l}\text { Política Social, } \\
\text { assistência } \\
\text { social, direito. }\end{array}$ & $\begin{array}{l}\text { Arlete de Brito } \\
\text { Abreu; Carla } \\
\text { Cecília Serrão } \\
\text { Silva; Jercenilde } \\
\text { Cunha Silva; Lília } \\
\text { Penha Viana Silva }\end{array}$ & UFMA & $\begin{array}{c}\text { Nordest } \\
\mathrm{e}\end{array}$ \\
\hline 6 & 2015 & $\begin{array}{l}\text { Revista de } \\
\text { Políticas } \\
\text { Públicas }\end{array}$ & $\begin{array}{l}\text { Proteção social, } \\
\text { SUAS, } \\
\text { implantação, } \\
\text { crise } \\
\text { Capitalista. }\end{array}$ & $\begin{array}{l}\text { Raquel } \\
\text { RaichelisDegenszaj } \\
\text { n; Berenice Rojas } \\
\text { Couto; Maria } \\
\text { Carmelita Yazbek }\end{array}$ & UFMA & $\begin{array}{c}\text { Nordest } \\
\mathrm{e}\end{array}$ \\
\hline
\end{tabular}




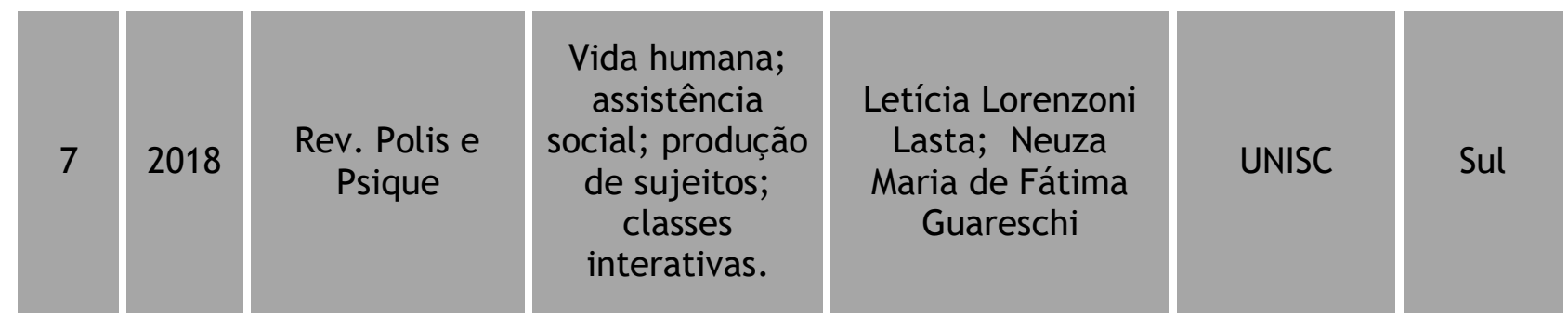

Fonte: Elaborado pelos autores (2020).

A partir da análise dos artigos apresentados no Quadro 3 e da revisão de literatura, foi possível constatar, de acordo com Paiva e Lobato (2017), que, a criação do SUAS, através de Lei, constituiu um avanço para a consolidação da assistência social como política, e um reforço daquilo que já vinha sendo implementado por outros dispositivos legais. Com a instituição do SUAS, a política de assistência social passa a ter uma nova configuração, que ressalta seu caráter de política pública não contributiva, descentralizada. Contudo, com mais de dez anos depois de sua criação, não se pode esquecer que o SUAS ainda tem um longo caminho a trilhar para sua efetivação.

Para Lencina (2018), nesse atual cenário, outro desafio é a participação da sociedade. A sociedade civil tem um papel de extrema relevância, pois não cabe apenas ao governo a discussão da política de assistência social. Assim, faz-se necessário que todos os atores sociais da política atuem, para que se saia de cena o Estado como poder central.

Abreu (2016) relata que o SUAS é uma política que tem grandes obstáculos para a sua implementação em todo país, que vão desde o financiamento, as diferentes expressões assumidas pela questão social em um país com considerável dimensão territorial, e ainda a crescente busca por assistência social no país, em virtude de um número cada vez maior de indivíduos em situação de pobreza extrema; além da precarização dos vínculos dos trabalhadores no SUAS.

\section{A Trajetória da Assistência Social e suas bases normativas enquanto Política Pública}

A Assistência Social no Brasil possui suas raízes na caridade, filantropia e solidariedade religiosa, baseadas em ações de assistencialismo, paternalismo, e/ou clientelistas, que concediam favores aos cidadãos, que eram vistos como pessoas desassistidas de direitos. Nesse contexto, de acordo com Paulo Netto (2005), é preciso 
analisar a Assistência Social tanto como uma relação entre classes sociais com desigualdades sociais, como também uma condição do Estado, que se torna mediador dessa questão que defende historicamente as ideias de igualdade e liberdade, práticas totalmente impostas às relações de favor e de dependência. A despeito da responsabilidade do Estado com as políticas de proteção social, este Estado do bemestar social encontra oposição em suas ações pela corrente liberal que se impõe dominante em muitos países e que são opostas à intervenção do Estado, comprometendo a assistência às populações mais vulneráveis.

De acordo com lamamoto (1982), até 1930 a Assistência Social estava relacionada ao paternalismo individual e institucional. Após as primeiras reformas no país, o Estado passou a reconhecer a Assistência Social no sentido de integração das massas em apoio ao governo. Ou seja, a institucionalização das políticas sociais no Brasil, estava relacionada à estrutura corporativista.

$\mathrm{Na}$ década de 1960 a sociedade brasileira enfrenta um processo de rearticulação, a partir do momento que a população reivindica por melhores condições de vida e de trabalho. Um novo quadro político é desencadeado após o golpe de Estado.

Segundo Couto (2010), o governo Getúlio Vargas centrou-se na relação capital/trabalho, assim a legislação tinha como base o pensamento liberal, na qual a intervenção do Estado buscava o consenso nas relações entre empregados/as e empregadores/as.

A partir da década de 1980, houve mudanças significativas no que diz respeito ao campo dos direitos sociais com o engajamento e a pressão da sociedade civil, durante esse período, em relação à discussão das políticas sociais, acarretando assim uma ampla articulação dos movimentos sociais.

A partir da Constituição Federal de 1988 os direitos sociais tiveram um reconhecimento significativo, pois a partir desta, nascia o cidadão, não apenas um homem brasileiro, mas sim um sujeito detentor de direitos, entre eles a Seguridade Social.

Nesse sentido a Seguridade Social implica que todo cidadão tenha acesso a um conjunto de certezas e seguranças que venham cobrir, diminuir ou precaver os riscos e as vulnerabilidades sociais. A partir dessa nova concepção foi instituído o reconhecimento do direito universal, independente se o cidadão contribuísse com o sistema previdenciário ou não (YASBECK, 2004, p.13). 
Com a democratização do processo político acontece a elaboração de leis sociais pelo Congresso, entretanto o Estado favorece apenas as questões emergenciais, deixando de lado os trabalhadores que não interferem na elaboração das leis sociais.

$\mathrm{Na}$ Constituição Federal, os artigos 203 e 204 idealizam a Assistência Social enquanto política, sendo a mesma de responsabilidade do Estado e direito de todo cidadão. Como ratifica o artigo primeiro da Lei Orgânica da Assistência Social (LOAS), $\mathrm{n}^{\circ} 8.742$ de 7 de dezembro de 1993, que dispõe sobre a organização da assistência social no Brasil. A Assistência Social, direito do cidadão e dever do Estado, é política de Seguridade Social não contributiva, que provê os mínimos sociais, realizada através de um conjunto integrado de ações de iniciativa pública e da sociedade, para garantir 0 atendimento as necessidades básicas.

A inclusão da Assistência na Seguridade Social foi uma decisão plenamente inovadora. Primeiro, por tratar esse campo como conteúdo da política pública, de responsabilidade estatal, e não como uma nova ação, com atividades e atendimentos eventuais. Segundo, por desnaturalizar o princípio da subsidiariedade, pela qual a função da família e da sociedade antecedia a do Estado. (...) Terceiro por introduzir um novo campo em que se efetivam os direitos sociais. SPOSATI (2009, p. 14).

Para Carvalho (2006), a Assistência Social deve atuar junto à população vulnerável que se encontra fora dos mecanismos e sistemas de segurança social obtidos pela via do trabalho, do usufruto das políticas públicas (saúde, educação, cultura, habitação, saneamento, entre outras) e da inserção em sociabilidades sócio familiares. A política pública de Assistência Social é vista como um direito do cidadão e dever do Estado, considerada como uma política de seguridade social não contributiva, pois todos têm acesso independentemente de contribuição à seguridade social. Tal política tem como marco a Constituição de 1988, por meio dos artigos 203 e 204.

A partir da Constituição de 1988 ocorreram outras regulamentações como a Lei Orgânica da Assistência Social (LOAS), o Estatuto da Criança e do Adolescente (ECA). Mais recentemente a aprovação do Sistema Único da Assistência Social (SUAS) e da Norma Operacional Básica da Assistência Social (NOB) conferem um novo status e um desafio maior à política pública de assistência social. 
O SUAS passou a articular maneiras e esforços para os benefícios socioassistenciais, através da execução de programas e benefícios, surgindo assim um sistema descentralizado, participativo, com o intuito de incluir a gestão da Assistência Social no campo da proteção social brasileira, sendo assim, promover maior envolvimento de suas ações. O SUAS materializa o conteúdo da LOAS, cumprindo no tempo histórico dessa política as exigências para a realização dos objetivos e resultados esperados que devem consagrar direitos de cidadania e inclusão social (PNAS, 2004, p. 33).

A NOBISUAS (BRASIL, 2005, p. 21) define ainda que a rede socioassistencial se organize a partir dos seguintes parâmetros: - Oferta, de maneira integrada, de serviços, programas, projetos e benefícios de proteção social para a cobertura de riscos, vulnerabilidades, danos, vitimizações, agressões ao ciclo de vida e à dignidade humana e à fragilidade; - Caráter público de corresponsabilidade e complementariedade entre as ações governamentais e não governamentais de assistência social evitando paralelismo, fragmentação e dispersão de recursos; Hierarquização da rede pela complexidade dos serviços e abrangência territorial de sua capacidade face à demanda; - Porta de entrada unificada dos serviços para a rede de proteção social básica através de unidades de referência e para a rede de proteção social especial por centrais de acolhimento e controle de vagas; - Territorialização da rede de assistência social sob os critérios de: oferta capilar de serviços baseada na lógica da proximidade do cotidiano de vida do cidadão; localização dos serviços para desenvolver seu caráter educativo e preventivo nos territórios com maior incidência de população em vulnerabilidades e riscos sociais; - Caráter contínuo e sistemático, planejado com recursos garantidos em orçamento público, bem como com recursos próprios da rede não governamental.

Com a implantação do SUAS, portanto, busca-se instituir um modelo de organização da política fundamentado na normatização e padronização dos serviços e da sua rede prestadora e, principalmente, na implantação de uma nova sistemática de financiamento. Bastante influenciado pela experiência da saúde, a gestão financeira da Assistência Social passou por modificações em seus mecanismos de transferência de recursos, nos critérios de partilha e na forma de distribuição. Com a finalidade de garantir a continuidade das ações e fortalecer a coordenação intergovernamental, a primeira mudança consiste na substituição dos antigos convênios firmados entre as 
esferas de governo por repasses automáticos e regulares. Prioriza-se o mecanismo de repasse denominado fundo a fundo, isto é, direto do Fundo Nacional de Assistência Social (FNAS) para os fundos estaduais e municipais.

A Gestão da Política na perspectiva do SUAS é tratada na Política Nacional de Assistência Social. De acordo com esta, a Política Pública de Assistência Social realiza-se, considerando as desigualdades socioterritoriais, a garantia dos mínimos sociais, ao provimento de condições para atender contingências sociais e a universalização dos direitos sociais (PNAS, 2004, p. 23).

Acompanhando a evolução da Assistência Social como política pública, destacase nesse processo a implantação e implementação do SUAS, elevando progressivamente a excelência na condução dessa política pública afiançadora de direitos sociais.

Pesam sobre os órgãos gestores da Política de Assistência Social a constante ameaça de extinção de Ministério e Secretárias, a instabilidade na contratação de recursos humanos e a diminuição do corpo técnico efetivo e, ainda a insegurança no que diz respeito aos recursos financeiros para gestão e implementação de ações pertinentes a essa área. Esses entraves vêm sendo acirrados diante do cenário nacional de congelamento de recursos.

Os gestores, comprometidos com as políticas sociais, estão intensificando as lutas e ações em defesa dos direitos sociais, numa conjuntura de subordinação da política social ao ajuste fiscal e às medidas de austeridade. Estudos realizados por Silva (2005) demonstram que a assistência social vem se construindo permeada por rupturas e continuidades com o conservadorismo que a originou e que a atravessa ainda, no processo de implementação do SUAS. Essa construção da história lenta está sofrendo na atualidade, mais um golpe em seu lento processo de constituição, perpetrado pelos governos conservadores recente e atual, através de um conjunto de medidas conservadoras de ajuste fiscal que retiram direitos da população brasileira e que impactam nas políticas de seguridade social, com claros sinais de regressão conservadora. Em primeiro lugar destacam-se os efeitos perversos da Emenda Constitucional $n^{\circ}$ 95/2016, que prevê o congelamento por 20 anos dos limites constitucionais para as despesas primárias da administração pública federal. Esse congelamento de recursos financeiros impacta diretamente sobre as políticas públicas, com destaque para as de seguridade social, especialmente aquela que ainda não foi 
consolidada em seu processo de implantação e implementação, a assistência social.

Além do congelamento dos limites constitucionais por 20 anos, o que já comprometeria a continuidade da construção do SUAS, há que se considerar o conjunto de contrarreformas previdenciária e trabalhista, que têm como fundamento, a expropriação de direitos já adquiridos e como discurso oficial o enfrentamento do déficit da previdência e do risco de sua extinção em futuro próximo ou a modernização da legislação trabalhista no sentido de facilitar a inserção do trabalhador no mercado de trabalho. A implementação destas medidas incidirá sobre o aumento da população desprotegida pelo trabalho a necessitar da proteção da assistência social, cujos recursos não acompanharão o crescimento da demanda. Necessário se faz então o fortalecimento dos instrumentos de gestão do SUAS, quais sejam o Plano de Assistência Social (PAS), o Orçamento, o Monitoramento, a Avaliação e a Gestão da Informação e o Relatório Anual de Gestão, de acordo com o texto da Política Nacional de Assistência Social. (BRASIL/PNAS/2004).

\section{Considerações Finais}

Esta investigação buscou trazer para o debate acadêmico uma discussão sobre o Sistema Único de Assistência Social, SUAS, por meio do estudo da política pública de Assistência Social. A partir das ponderações apresentadas no texto pode-se inferir que o principal foco analítico da política pública está na identificação de que através da implementação do SUAS, a Assistência Social chegará a ser consolidada como uma efetiva política de proteção social. A legítima efetivação da assistência social só ocorrerá com o fortalecimento do estado de bem-estar social e com o emprego efetivo dos instrumentos de gestão do SUAS. A Legislação avançou ao instituir legalmente aquilo que já vinha sendo implementado por outros dispositivos normativos. A partir dela e dos debates que se seguiram para a sua construção, definiu-se a nova configuração institucional da política de assistência social, enfatizando seus preceitos de política pública não contributiva e desmercadorizada. Ainda se percorrerá um longo caminho para a consolidação da Lei, mas sem dúvidas, o processo de sua formulação trouxe ganhos à democracia e ao fortalecimento de sua institucionalidade na sociedade brasileira.

Porém, desde meados de 2016 estamos vivendo um contexto de ajuste fiscal de implementação de contrarreformas sociais que afetam diretamente os diretos sociais. 
Elas envolvem tanto serviços como benefícios, alcançando também aspectos referentes a institucionalidade e ao arranjo federativo da política, e provocam a desconstrução dos fundamentos que caracterizam a lógica da estruturação e funcionamento do próprio Sistema. O quadro atual é de uma política sem vinculação constitucional de recursos e alicerçada na participação social, o risco de redução do Programa Bolsa Família, a desconfiguração do BPC- Benefício de Prestação Continuada, a desvalorização das instâncias de pactuação e a interpretação das conferências como meras consultas desestruturam fortemente as bases do SUAS e ameaçam a efetivação do direito e o sentido da constituição cidadã. Além da repetição de práticas que reiteram uma assistência social pequena, pontual, seletiva, preconceituosa e higienista. Difícil algum dia ter imaginado tamanhos retrocessos como vivenciamos atualmente no período do des-governo do presidente Bolsonaro.

Estamos novamente protagonizando a resistência e luta coletiva em defesa do SUAS, da Seguridade Social, de um projeto popular, no enfrentamento das desigualdades, em oposição a tudo que ameaça a democracia e a história de ruptura com a apartação social e política no país. Para a efetivação da Política Nacional de Assistência Social, em um projeto voltado para o fortalecimento da seguridade social, garantia de direitos, ampliação de oportunidades e enfrentamento da desigualdade, faz-se necessário o aprimoramento, da cooperação e coordenação intergovernamental, o fortalecimento das instâncias e dos instrumentos de pactuação intergestores, e da qualidade do monitoramento das ações e da gestão pública nas três esferas de governo. Melhorar a capacidade estatal no contexto das relações federativas implica em enfrentar um amplo conjunto de desafios, entre os quais podem ser lembrados o reforço da capacidade operacional e técnica nas três esferas de governo na gestão da política. Todos esses apontamentos para o futuro da assistência social devem compor uma agenda de direitos no âmbito da seguridade social, sustentada pelo diálogo com os mais variados setores da sociedade, garantindose o protagonismo da população. A participação social não deve ser apenas legitimadora da política, mas constitutiva, de modo a assegurar o controle das ofertas e de sua qualidade. Essa parece ser a direção, dentro de um cenário democrático, da conquista civilizatória promovida pela $\mathrm{CF} / 88$, que dará finalmente sentido a uma política nacional efetiva através do SUAS. 


\section{Referências}

ABREU, M. H. E. Território, política social e serviço social: caminhos e armadilhas no contexto do social-liberalismo. Campinas: Papel Social, 2016.

BRASIL. Constituição Federal de 1988.

BRASIL. Norma Operacional Básica do Sistema Único de Assistência Social, 2005.

BRASIL. Política Nacional de Assistência Social (PNAS), 2004.

CARVALHO, M. C. B. Assistência Social: reflexões sobre a política e sua regulação. In: Revista Serviço Social e Sociedade, n. 87 (SUS e SUAS), ano XXVI. São Paulo: Cortez ed., 2006.

COUTO, B. R. O direito social e a assistência social na sociedade brasileira: uma equação possível? 4. ed. São Paulo: Cortez, 2010.

GIANEZINE, K. Políticas Públicas: definições, processos e constructos no século XXI. 2016. Disponível em: https://sistemas.uft.edu.br/periodicos. Acesso em: 15 jan. 2020.

IAMAMOTO, M. V.; CARVALHO, R. Relações sociais e Serviço Social no Brasil: esboço de uma interpretação histórico-metodológica. São Paulo: Cortez, 1982.

LENCINA, D. B. S. A Assistência Social como política pública. RELACult: Revista Latino-Americana de Estudos em Cultura e Sociedade, v. 4, n. 4, p. l-13, mai., 2018. LIMA, W. G. Política pública: discussão de conceitos. Revista Interface (Porto Nacional), Porto Nacional, n. 05, p. 49-54, out. 2012.

LIMA, P. P. F. Implementação como interpretação e aprendizado: sobre a implementação das averiguações cadastrais no Cadastro Único de programas sociais. Boletim de Análise Político-Institucional (Ipea), n. 13, p. 59-63, out. 2017.

PAULO NETTO, J. P. Ditadura e Serviço Social. São Paulo: Cortez, 2005.

PETERS, M. A. Economias biopolíticas da dívida. Cadernos IHUideias, São Leopoldo, ano 14, v.14, n. 236, p. 3-16, 2016.

RAEDER, S. Ciclo de Políticas: uma abordagem integradora dos modelos para análise de políticas públicas. Perspectivas em Políticas Públicas. Belo Horizonte, v. VII, n. 13, p. 121-146, jan/jun 2014.

SILVA, J. F. S. Teoria e prática no trabalho profissional do assistente social: falsos e verdadeiros dilemas. Serviço Social \& Realidade, Franca, v. 14, n. 2, p. 133-54, 2005. SPOSATI, 2009. Concepção e gestão da proteção social não contributiva no Brasil. Brasília: Ministério do Desenvolvimento Social e Combate à Fome, UNESCO, 2009.

YASBEK, M. C. As ambiguidades da Assistência Social Brasileira após 10 anos de LOAS. Revista Serviço Social \& Sociedade, v. XXV, n. 77, p. 11-29, mar. 2004. 